\title{
Image Case:Loculated Abdominal Collection following Leaking Hepatocellular Carcinoma
}

\author{
Ahmed S Bihery ${ }^{1}$, Emad H Emara ${ }^{2}$ \\ ${ }^{I}$ Tropical Medicine Department, Faculty of Medicine, Zagazig University, Egypt \\ ${ }^{2}$ Radiodiagnosis Department, Faculty of Medicine, Zagazig University, Egypt
}

Corresponding author: Ahmad Bihery

email:

ahmedbihery@

yahoo.com

mobile:

+2(010) 0089628

Received : $10 / 2 / 2013$

Accepted after

revision: $19 / 2 / 2013$
A 60 years old women presented by progressive abdominal distension and abdominal pain. When presented ultrasound guided abdominocentesis confirmed intraperitoneal hemorrhage further assessment by abdominal-pelvic CT scans showed leaking sub capsular hepatic focal lesion consistent with hepatocellular carcinoma. The patient was treated conservatively and 2 months later she experienced recurrent abdominal pain and sub acute intestinal obstruction. Ultrasonographic examination showed intrabdominal loculations(figure 1). The differential diagnosis of this condition includes intraperitoneal hemorrhage due to other causes, abdominal TB and recurrent spontaneous bacterial peritonitis in ascetic patients..

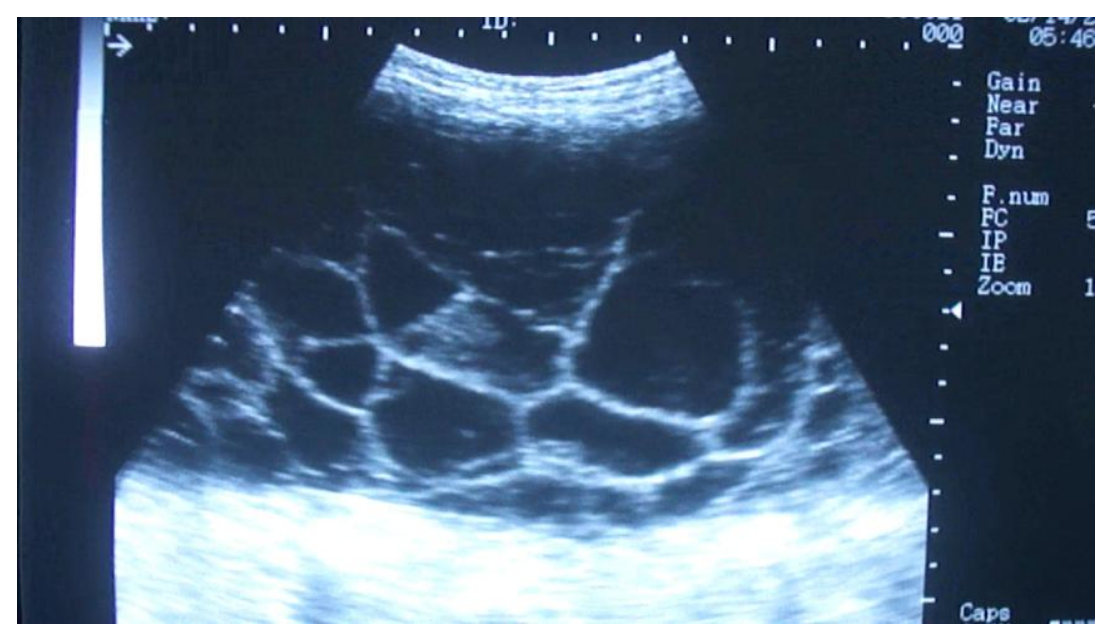

Figure 1: Intraabdominal fibrotic loculations 